\title{
A versatile dispenser for commercial monkey chow reinforcement
}

\author{
HANS ENGELE, BRUNO PREILOWSKI, and MICHAEL REGER \\ University of Tuebingen, Institute of Psychology, Aussenstelle Weissenau \\ Ravensburg/Weissenau 7980, West Germany
}

\begin{abstract}
A dispenser is described that can deliver a wide variety of foodstuffs of almost any consistency. Despite compact size, storage capacity is sufficient for several days of unattended operation. Computer-compatible logic allows flexible applications in animal housing facilities and experimental setups. Its application in delivering regular monkey chow as reinforcement in experiments is discussed.
\end{abstract}

In this paper, we describe a monkey chow dispenser modeled after the grain feeder developed by Ferster and Skinner (1957) for pigeons. Katzev and Hofmann (1977) designed a similar apparatus for use with rats. The monkey system noted here incorporates additional features, including a computer-compatible interface logic, which allows for flexible applications both in regular animal housing facilities and in various experimental setups. The magazine of the dispenser takes approximately $1.2 \mathrm{~kg}$ of food of almost any consistency, sufficient for several days of unattended operation. It allows the monkey access to the food for a well defined time period, and with a specified degree of ease.

Prior to the development of this system, we considered the commonly used belt or magazine dispensers but found them too limited in storage capacity, too time-consuming to refill, too bulky, and often unreliable.

\section{APPARATUS}

The apparatus shown in Figure 1 consists of a $84 \mathrm{~mm}$ (width) x $270 \mathrm{~mm}$ (depth) x $425 \mathrm{~mm}$ (height) chassis made of 4-mm DURAL. All interiors are suspended from the left-hand (1), bottom (2), and back (3) walls, so that the right-hand wall and front cover (4) can easily be removed if cleaning or repair becomes necessary (for ease of drawing, the right-hand wall is not shown in Figure 1). Only the food magazine (5) (2-mm DURAL, welded; drawn separately in Figure 1) plugs with its axis (6) into a pair of Teflon sockets (7), serving as a rotating support in both side walls.

Whenever the dispenser receives a trigger signal, the magazine is made to swing clockwise around its axis, pushed by a heavy solenoid (8), until the food tableau

Citation of the authors is in alphabetical sequence. This research was conducted at the University of Konstanz and supported by the Deutsche Forschungsgemeinschaft (Pr 117/7-1). The help of the central mechanical shop facilities of the University of Konstanz in the construction of the apparatus is gratefully acknowledged.

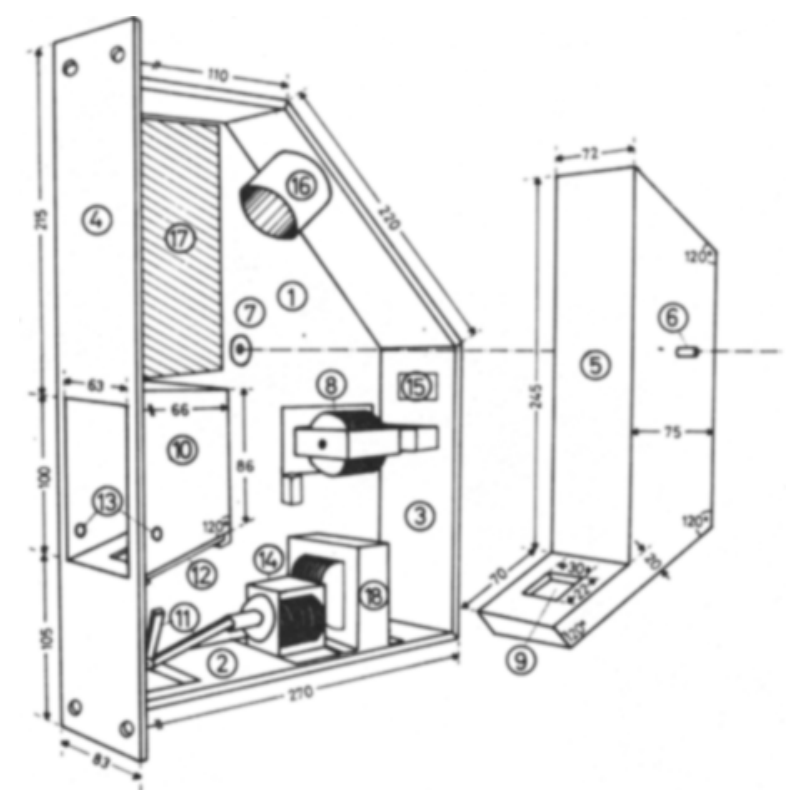

Figure 1. Food dispenser with one side wall removed and magazine taken out. $1=$ side cover, $2=$ bottom cover, $3=$ back cover, $4=$ front cover, $5=$ food magazine, $6=$ axis, $7=$ Teflon socket, $8=$ push solenoid, $9=$ food tableau, $10=$ access box, 11 = snap-in hold, 12 = interchangeable mask, 13 = light barrier, $14=$ unlock solenoid, $15=$ manual trigger, $16=$ refill tube, $17=$ printed circuit board, $18=$ transformer.

(9) hits the food access box (10) from underneath. In this position, the magazine is automatically arrested by the snap-in mechanism (11), which latches with a small plastic wedge at the magazine's bottom.

At this point, the monkey can grasp for food by introducing his hand through the opening in the front cover into the food access box (10). An interchangeable mask (12) cut from 2-mm DURAL and individually adapted to the animal's finger size prevents the monkey from drawing food with more than two fingers at a time. As soon as the hand is retracted, an infrared light barrier (13) signals the dispenser's logic to engage the "unlock" solenoid (14), whereby the magazine is 
released, swinging back into its starting position, pulled by its own weight and a tiny spring that is not shown in Figure 1.

If the animal does not reach into the food access box within a defined period of time (adjustable from approximately 1 to $100 \mathrm{sec}$ ), the magazine automatically retracts. It will not retract as long as the animal has its hand in the food access box, however long this may be.

Manual triggering may be accomplished via the monostable "manual trigger" push button (15), which should be out of the animal's reach. If necessary, the push button can be replaced by a key-operated switch.

For noise-abatement purposes, rubber is applied to all points of impact of the moving magazine with other parts of the apparatus. The "push" solenoid (8) is mounted on four elastoplastic silicon socket/washer combinations.

The food access box is illuminated through a Plexiglas cover. This illumination remains dim as long as the dispenser is idle. It increases in intensity during operation, retuming to the dim state when the magazine retracts.

In order to prevent spilled food from locking the snap-in mechanism (11), a $45 \times 35 \mathrm{~mm}$ hole is cut into the bottom of the chassis, just below the food access box. On the opposite side, another hole drilled into the top cover of the chassis is fitted with a premium-grade (ceramic) highly insulated male plug (not shown in Figure 1) with six pins. This plug is used for connecting the $220-\mathrm{V}$ ac power supply (two pins), the protective ground (connected to the chassis), the computer ground (isolated from the chassis), the trigger signal from the computer (active low, 100-msec nominal pulse width, maximum $1 \mathrm{~mA}$ of load at TTL level when low; no load when high), and the busy signal to the computer (active low, low-power Schottky TTL fan out 10). Both lines of the power supply are adequately secured by fuses, inside the chassis $(250 \mathrm{~V}, 1 \mathrm{~A}$, slow blow).

In the rear, oblique wall of the dispenser, there is a hole $40 \mathrm{~mm}$ in diameter (smaller than a rhesus hand; to be adapted accordingly for different species), through which a PVC tube (16) projects about $10 \mathrm{~mm}$ into the food magazine for refilling.

With the exception of the transformer (18), light barrier (13), and ac filters, all electronic components are located on the printed circuit board (17), with analog and digital function blocks separated. The filters must be placed as close as possible to their respective solenoids. Details on circuitry (Figure 2) and parts lists can be obtained from the authors.

We have been using the new dispenser for 3 months in an experimental investigation of certain types of manipulatory tests with rhesus monkeys. Animals were run under regular housing conditions with free access to the manipulanda $24 \mathrm{~h} /$ day. Every successful trial was rewarded. With the exception of occasional replacement of the light bulb illuminating the food access box, no down-times were incurred. Reinforcement with ordinary

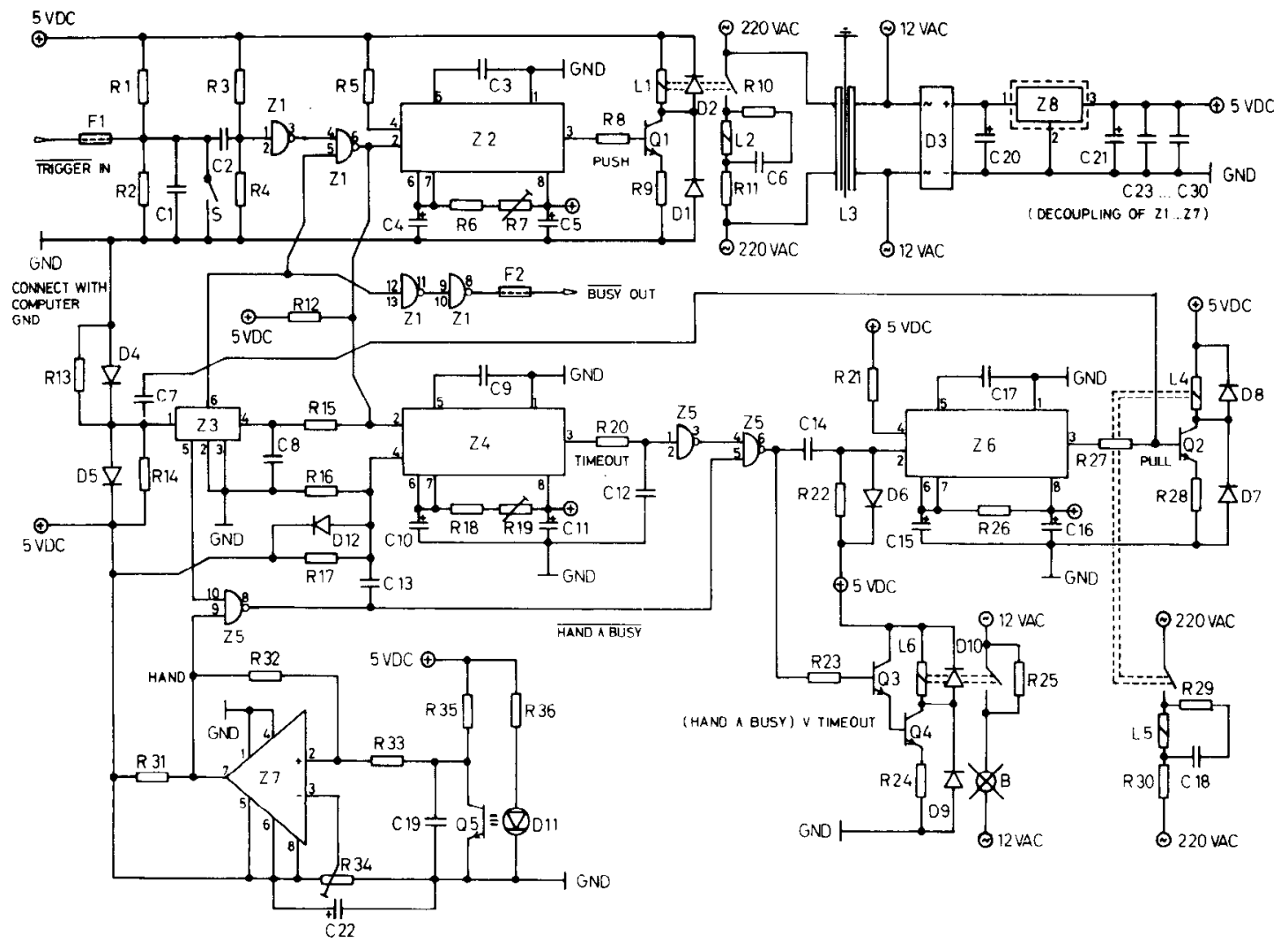

Figure 2. Electronic circuitry (details can be obtained from the authors). 
monkey chow proved to be very effective in achieving homogeneous distributions of manipulatory activity and performance.
Katzev, R. B., \& Hofrman, D. A. An economical dispenser to improve control of food reinforcement in the rat. Behavior Research Methods \& Instrumentation, 1977, 9, 565-566.

\section{REFERENCES}

Fenster, C. B., \& Sxinner, B. F. Schedules of reinforcement. New York: Appleton-Century-Crofts, 1957.
(Received for publication September 21, 1982; revision accepted December 7, 1982.) 